\title{
The law of the canals and postural clinic*
}

\author{
Pierre-Marie Gagey ${ }^{1}$
}

\section{ABSTRACT}

An hypothesis on the construction of the coherence of the perception of space, visual and proprioceptive, through the three afferents, retinal, oculomotor and canalicular, allows us to offer a way to deconstruct this consistency by an optical prism. And this deconstruction exhibits the organization between space perception and regulation of the postural tonic activity.

Keywords: Posturology; Perception of space; prism; oculomotor system.

\section{INTRODUCTION}

The perception of space is not built independently on each sensory channel. This very old hypothesis, already proposed by Aristotle in his 'peri Psuches', was studied for the perception of visual space that is built from the retinal afferents and from the oculomotor proprioceptive afferents..$^{(1-5)}$

To check that this assumption is also true as regards visual and vestibular afferents, it is possible to take into account the very particular anatomy and physiology of the semicircular canals. Each canal, indeed, specifically perceives the angular accelerations according to the plane, the sense and the direction of the acceleration relative to the plane of this channel. ${ }^{(6-11)}$ So, an angular acceleration parallel to the plane of the right posterior canal and directed to the rear and the right side provokes the appearance of excitatory afferences only from the cupule of this canal (Fig. 1).

And, in the absence of movements of the eyeballs, the head movement caused by these angular accelerations is accompanied, on the retina, by a sliding of the image of the environment, which occurs along a meridian of the eye, parallel to the vector of the angular acceleration. If, during the 'ontogenesis', the perception of space is not built independently for the visual channel and the vestibular canal, traces of this privileged link between the plans of the semicircular canals and the directions of visual space must be found.

Knowing roughly the plans of the semicircular canals it is then possible to determine, geometrically, these ocular meridians "corresponding" to the semicircular canal plans. The left rear channel plan, for example, forms an angle of $71^{\circ}$ relative to the horizontal plane of Reid's stereotactic system (Tétha1 on figure 2 ) and an angle of about $55^{\circ}$ compared to the sagittal plane of the same system (Tétha2 in Figure 2). ${ }^{(12)}$ The section of the eye globe by a plane parallel to the plane of the canal and passing through the center of the globe matches the meridian along which the image of the environment slips during the movements whose accelerations stimulate the left posterior canal.

It may be noted that the same retinal slip is caused by an eyeball rotation around an axis perpendicular to this plan.

This last remark predicts a privileged relationship between each semicircular canal and the oculomotor muscle/muscles, that, in the vicinity of the primary position, bring about a rotation around an axis perpendicular to the plane of these semi-circular canals. This privileged relationship has in fact been described by several authors. ${ }^{(13-16)}$

Corresponding Author: Pierre-Marie Gagey. Institut de Posturologie Paris, Paris, France. E-mail: pmgagey@club-internet.fr ${ }^{1}$ Institut de Posturologie Paris, Paris, France.

Financial support: No financial support.

Submission date 2 December 2015; Acceptance date 23 February 2016; Publication online date 9 March 2016

\footnotetext{
* Lecture given at the College de France, Paris, on November the 16th 1996, to the members of "L'Association Française de Strabologie" interested by the postural control. Reporting from the Pr. P.V. Bérard.
} 
A prism deflects the visual space in a single direction that can be identified by the position of the prism base. If, during the ontogenesis, the perception of the space is constructed coherently for the visual and vestibular sensory channels, one must find some relationship between the planes of the channels and the position of the base of the prism.

A prism, for example, whose base is located at 125 - causes, on the retina, a deviation of the visual space approximately parallel to the retinal meridian «associated» with the plane of the right posterior canal (Fig. 3).

The apparent movement of the image of the environment on the retina of the right eye corresponds to a movement of the eyeball, near the primary position, produced by the small oblique muscle oculomotor. To verify that this relationship between the planes of the canals and the position of the base of the prism can be found experimentally, a retrospective study was undertaken on the records of postural patients of the Posturology Institute treated by the wearing of optical prisms.

Since the publications of Magnus ${ }^{(17)}$ it is known, in fact, that the perception of the space is involved in the regulation of the postural tone. It is therefore possible to provide a study, of the phenomena involved in the perception of space through the postural tone.
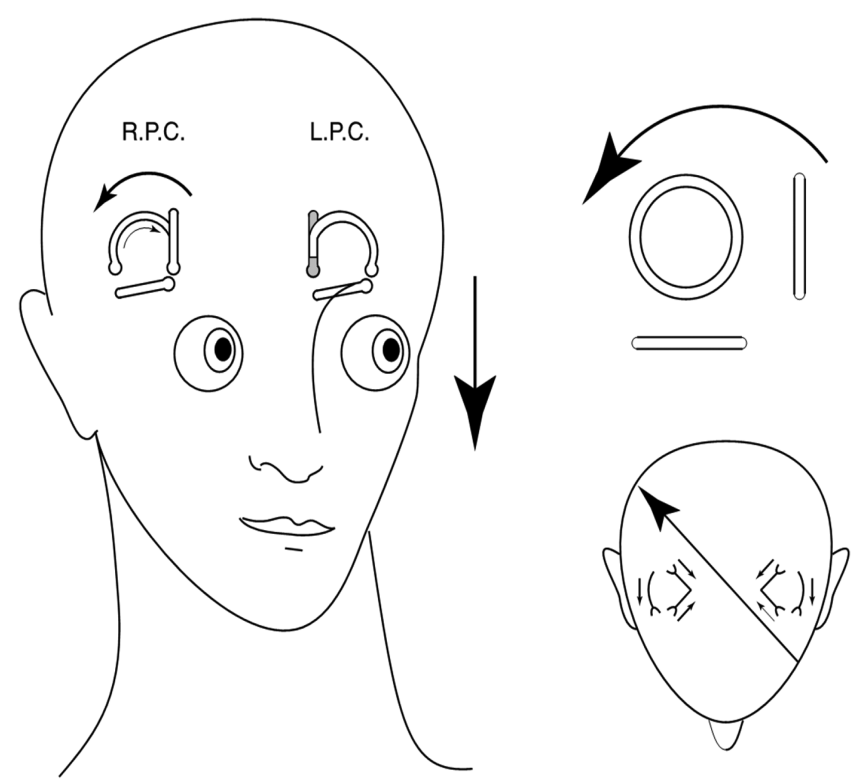

Figure 1. An angular acceleration in the plane of the right posterior canal causes movement of the endolymph, exciting only the right posterior canal. If the eyeball is fixed, the movement induced by this acceleration is accompanied by a retinal slip along the meridian of the eye, parallel to the plane of the right posterior canal and in the sense and the direction of the acceleration.

\section{METHODS}

\section{Subjects}

The records of 197 patients who had consulted the Institute Posturology for symptoms related to functional disorders of the control of the orthostatic posture, have been selected because they contained a precise account of a normalized

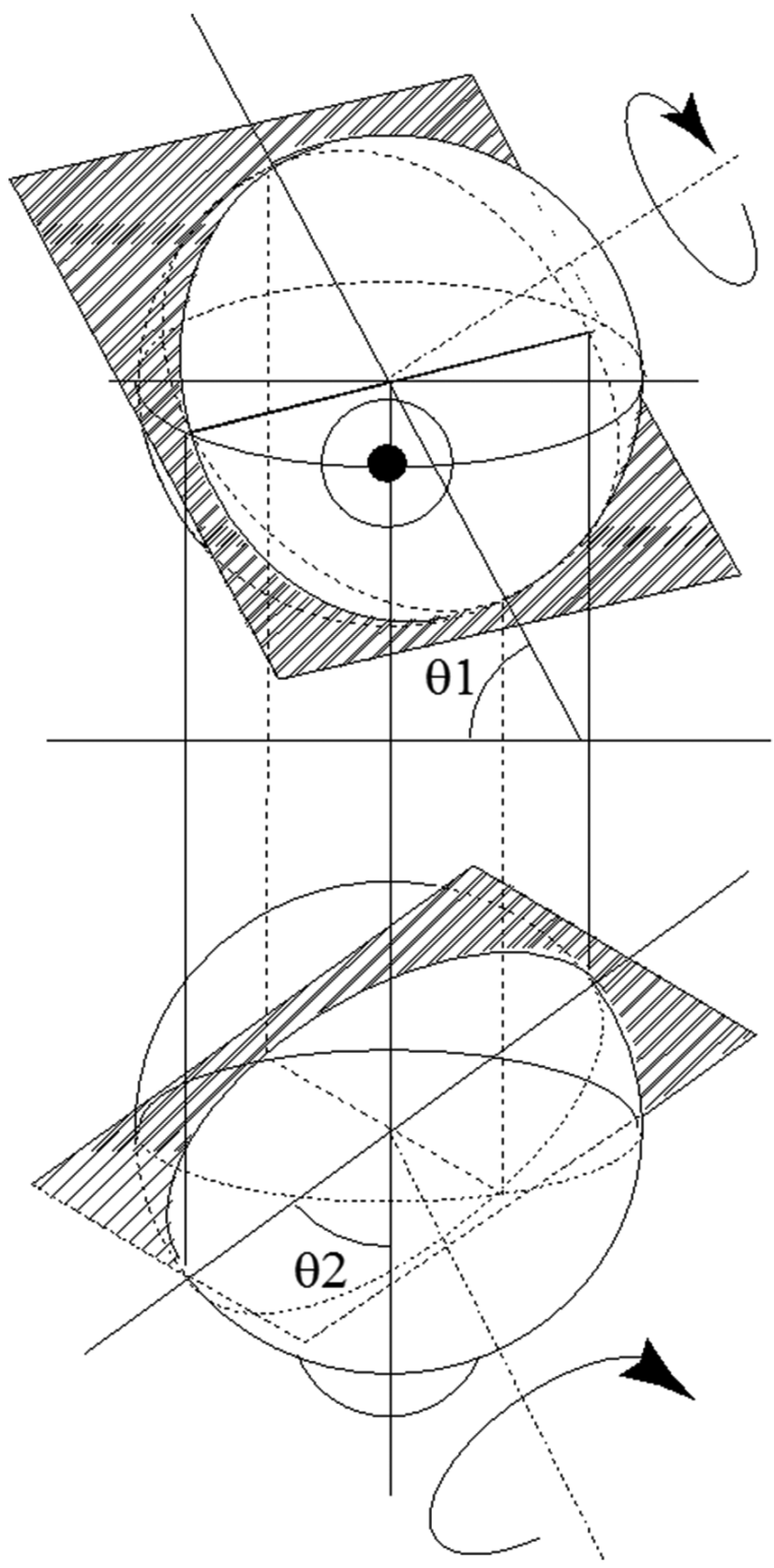

Figure 2. Descriptive study of the section of an eyeball by a plane parallel to the left posterior canal and going through the center of the eye. Tétha $1=55^{\circ}$, tétha $2=71^{\circ}$ according to the stereotactic reference plane of Reid (Blanks et al., 1975.b) 


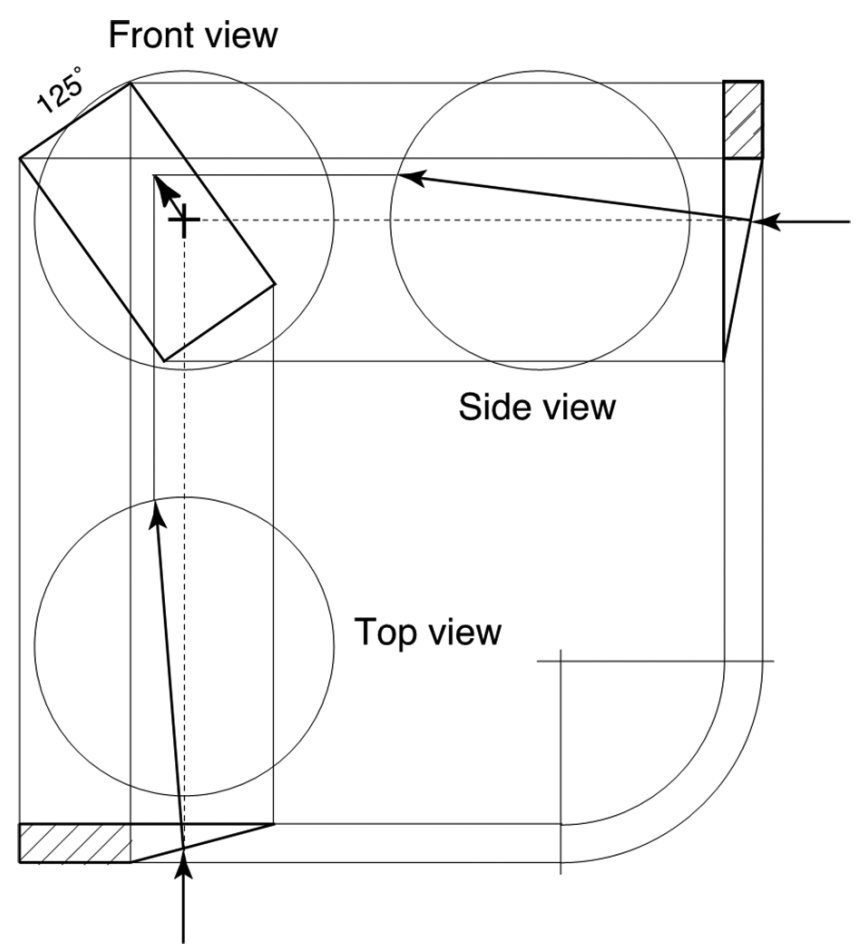

Figure 3. Descriptive study of the deviation of the visual space by a prism whose base is located at $125^{\circ}$. The deviation of the visual space is approximately parallel to the retinal meridian "associated" to the right posterior semicircular canal. The apparent movement of the image of the environment on the retina of the right eye corresponds to a movement of the eyeball, adjacent the primary position, produced by the oculomotor muscle small oblique.

postural clinical examination assessment of their postural tone, with and without the wearing of an optical prism whose base position was known.

These patients complained of dizziness and/or of instability, without abnormalities of the vestibular functional tests, or of various pains of the body axis when they stood upright quiet (back pains, neck pains, etc.).

\section{Evaluation of the postural tone}

The quantification of postural tone chosen for this study is the spin movement observed during the stepping test of Fukuda-Unterberger. ${ }^{(18)}$ This spin parameter was studied among a population of normal subjects, the distribution of its random fluctuations between two tests performed in similar conditions with intervals of a few minutes or of weeks, is known: the average differences between two similar paired tests is $0^{\circ} \pm 25^{\circ}$. $^{(14)}$ The technique of the stepping test described by Gagey \& Weber (19) was respected among the patient population studied. It is known that variations in the symmetry of the postural tonus induce systematic variations of the spin movement during the stepping test. ${ }^{(18,20)}$
Positions of the base of the prism

In accordance with what has been stated in the introduction, the studied positions of the base of the prism are noted counterclockwise, from a left temporal position: $0^{\circ}, 55^{\circ}, 125^{\circ}, 180^{\circ}, 235^{\circ}, 305^{\circ}$. All the subjects in this study achieved two stepping tests, one without a prism and one with a prism in, at least one of these positions of the base of the prism. No subjects repeated the stepping test in all the possible positions of the prism base. The position of the base of the prism studied on a given subject was determined by the other tests of his postural clinical examination showing the ability to change the postural tone of this subject by a prism of three prismatic diopters placed in this position.

\section{RESULTS}

The distribution of the fluctuations of the spin movement induced by the wearing of the prism is very significantly different from the distribution of the random variations of the same movement $(p<0.001)$, whatever the position of the base of the prism (Fig. 4):

The direction of the change of the spin movement depends on the position of the base of the prism (Fig. 4):

- sometimes under the effect of the prism, the subject turns more towards his right when the base of the prism is set at $0^{\circ}$ or $125^{\circ}$ or $235^{\circ}$ (negative values of the difference of the spins with and without a prism).

- sometimes he turns more toward his left when the base of the prism is positioned at $55^{\circ}$ or $180^{\circ}$ or 305 - (positive values of the difference of the spins with and without a prism).

\section{DISCUSSION}

The scope of this statistical analysis is limited. It deals only about subjects with functional disorders related with the orthostatic posture. However, a similar study was made on normal subjects, but it dealt only with the positions $0^{\circ}$ and $180^{\circ}$ of the base of the prism and only a small number of subjects. ${ }^{(21)}$ However the results of the study of Ushio and coll. are consistent with this analysis.

Each subject has been studied in only one position of the base of the prism; the described differences between all the positions of the base of the prism may then be reported to interindividual differences. However a study, close to the work presented in this paper, was carried out on normal subjects with rotating prisms, which, in eight seconds, explored all the possible positions of the base of the prism for the same subject. ${ }^{(22)}$ And the results of Séverac et al. also show a difference in the direction of the postural response according to the position of the prism 

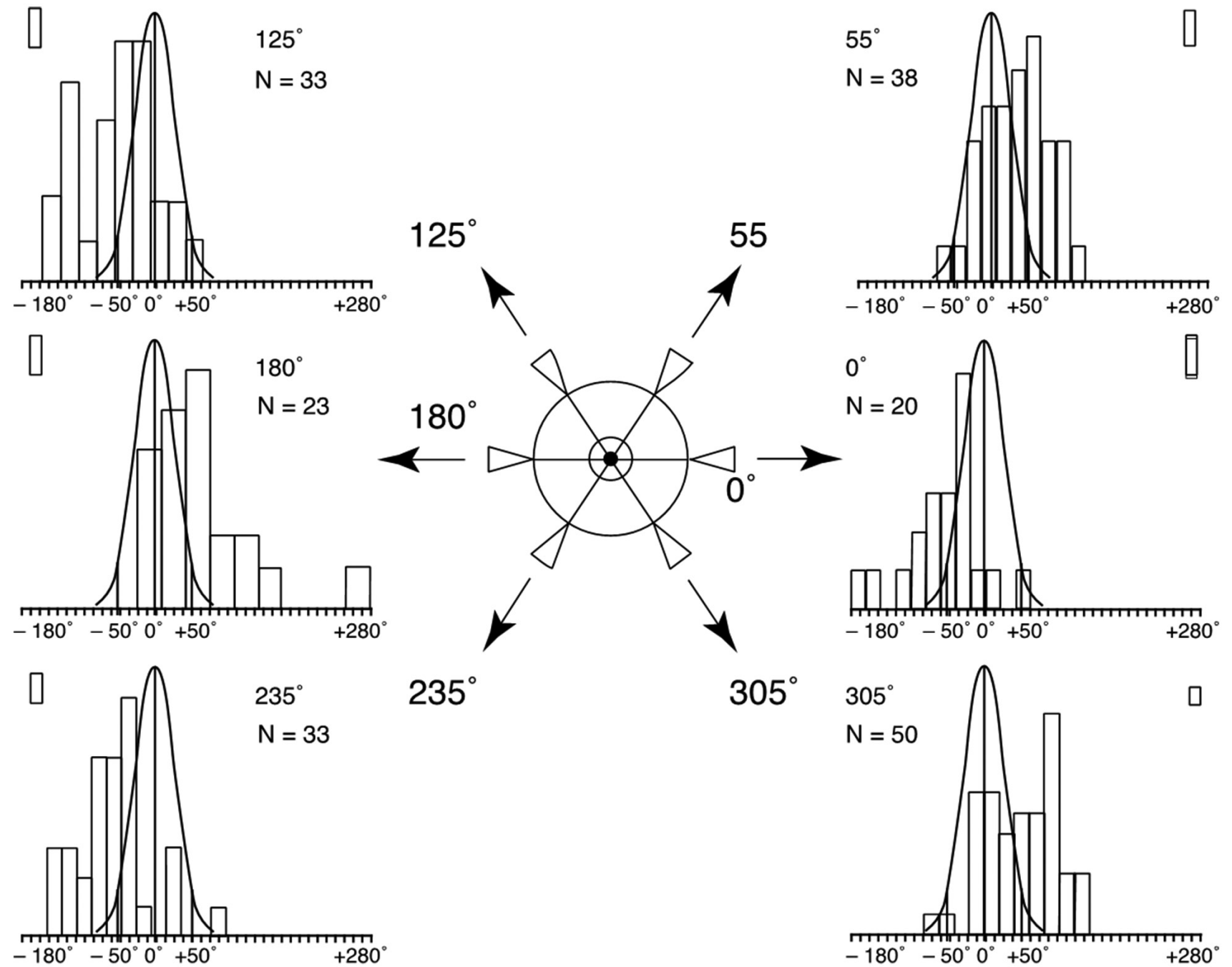

Figure 4. Spin variations observed for different positions of the base of the prism. - Center: Diagram showing the different studied positions of the base of the prism in front of the patient's eye. - On the sides: each of the six positions of the base of the prism, histogram of the variation of the spin movement produced by the establishment of the prism. The Gaussian curve recalls the theoretical normal distribution of the random variations of the spin movement.

base. The concordance of the results of Séverac et al. with these results ends here because the differences between the protocols do not allow a more precise comparison.

\section{CONCLUSION}

The reported clinical facts do not prove that the perception of space, during the ontogenesis, is organized consistently between the sensory channels, vestibular and visual, but they certainly make the hypothesis more likely.

\section{REFERENCES}

1. Cynader M, Berman N, Hein A. Cats raised in a one directional world: effects on receptive fields in visual cortex and superior colliculus. Exp Brain Res. 1975;22:267-280.

2. Cynader $M$, Berman $N$, Hein A. Recovery of function in cat visual cortex following prolonged deprivation. Exp Brain Res25, 139-56. 1976;25:139156.
3. Blakemore C, Sluyters RV, Peck C, Hein A. Development of cat visual cortex following rotation of one eye. Nature. 1975;257:584-586.

4. Hein A, Vital-Durand F, Salinger W, Diamond R. Eye movements initiate visual-motor development in the cat. Science. 1979;204:1321-1322.

5. Hein A. La structuration de l'espace visuel peut-elle se développer en I'absence des informations proprioceptives oculomotrices? Critique de la Posturologie. 1987;12:1-4.

6. Ross D. Electrical studies on the frog's labyrinth. J Physiol (London). 1936;86:117-146.

7. Löwenstein $O$, Sand $A$. The individual and integrated activity of the semicircular canals of the elasmobranch labyrinth. J Physiol (London). 1940;99:89-101.

8. Adrian E. Discharges from vestibular receptors in the cat. J Physiol (London). 1943;101:389-407.

9. Zotterman Y. The microphonic effect of teleost labyrinth and its biological significance. J Physiol (London). 1943;102:313-318.

10. Estes M, Blanks R, Markham C. Physiologic caracteristics of vestibular first-order canal neurons in Cat. I. Response plane determination and resting discharge characteristics. J Neurophysiol. 1975;38:1232-1249. 
11. Blank R, Estes M, Markham C. Physiologic caracteristics of vestibular firstorder canal neurons in Cat. II. Response to constant angular acceleration. J Neurophysiol. 1975.;38:1250-1268.

12. Blanks R, Curthoys $L$, Markam C. Planar relationships of the semicircular canals in man. Acta Otolaryngol (Stockh). 1975;80(191-200).

13. Nò RLd. The regulation of eye positions and movements induced by labyrinth. Laryngoscope. 1932;42:233-332.

14. Weber $B$, Gagey $P$, Noto $R$. La répétition de l'épreuve modifie-t'elle l'exécution du test de Fukuda? Agressologie. 1984;25:1311-1314.

15. Cohen B, Suzuki J, Shanzer S, Bender M. Semi-circular control of eye movements. In: Bender M, editor. The oculomotor systemHarper \& Row, New York. New York: Harper \& Row; 1964.

16. Ito $\mathrm{M}$, Nisimaru N, Yamamoto $M$. Pathways for the vestibulo-ocular reflex excitation arising from semicircular canals of rabbits. Exp Brain Res. $1976 ; 24: 257-271$
17. Magnus R. Körperstellung. Berlin: Springer; 1924.

18. Fukuda T. The stepping test. Two phases of the labyrinthine reflex. Acta Otolaryngol (Stockh). 1959;50(2):95-108.

19. Gagey P, Weber B. Posturologie Régulation et dérèglements de la station debout. Paris: Masson; 1995.

20. Ushio N, Hinoki M, Baron J, Gagey P, Meyer J. The stepping test with neck torsion: proposal of a new equilibrium test for cervical vertigo. Practica Otologica Kyoto69, Sup3, 1369-79 (En japonais). 1976;69(Sup.3):13691379.

21. Ushio N, Hinoki M, Nakanishi K, Baron J. Rôle of oculomotor proprioception in the maintenance of body equilibrium; correlation with the cervical one. Agressologie. 1980;21(E):143-152.

22. Séverac $A$, Bessou $P$, Pagès $B$. Unusual visual stimulation in dynamic balance conditions: proposal for a space motion sickness test. Adv Space Res. 1994;14(8):389-394. 